\section{THINK BIG}

\author{
Signs of life.
}

\section{BY GREGORY BENFORD}

W hen Judy found the strong emission lines of sulphur dioxide in a planetary atmosphere, she knew they had to be wrong. She took the data upstairs.

"A deep sulphur haze covering the whole planet?" her supervisor agreed. "Never happen. Even Krakatoa didn't do that to half an optical depth."

But the measurements held up. The planet was 579 light years away, had a surface temperature of $24^{\circ} \mathrm{C}$, and the oxygenrich atmosphere had deep carbon dioxide lines, too. In shorts and a T-shirt, Judy went for a run along the Charles River to clear her mind. It was $29^{\circ} \mathrm{C}$ on a clear day, three weeks before Christmas, and the maple trees in Boston hadn't yet turned red.

Back at MIT, she ran a full climate model and found that the planet's star, a G4 type, would heat the surface to $38^{\circ} \mathrm{C}$ unless she included the sulphur haze. "That's what's keeping the surface at $24^{\circ} \mathrm{C}$," she told her professor.

"Um. Any spectral lines from pollution?"

"Sure - carbon dioxide, the sulphur."

"That must be natural somehow."

"Why? The $\mathrm{CO}_{2}$ keeping Boston warm is from us."

It took another year to prove the case: the planet was being geoengineered with stratospheric sulphur aerosols. "Their civilization went down our same path, burning fossil fuels," Judy said at a press conference at the next meeting of the American Geophysical Union. The press headlined the Aliens Discovered! angle, but Judy persisted. "So they're no smarter than we are. Now, they're managing their way out of it."

She didn't like the media circus that erupted and so she fled to Europe. But there, protestors accused her of advocating "alien technology transfer" to Earth. As the world's weather was steadily worsening, this didn't seem to be such a bad idea.

But then the continuing telescopic searches turned up a world that was orbiting beyond the nominal 'habitable zone' of a $\mathrm{K}$ star, but that was unaccountably warm. Judy and her

\section{DNATURE.COM}

\section{Follow Futures:}

3. @atureFutures

ff go.nature.com/mtoodm team - by now she had plenty of grants found CFCs in that atmosphere; the same molecules that had brought grief to Earth's ozone layer in the twentieth century. Careful analysis of the telescopic data revealed a few dozen pixels showing oceans and land

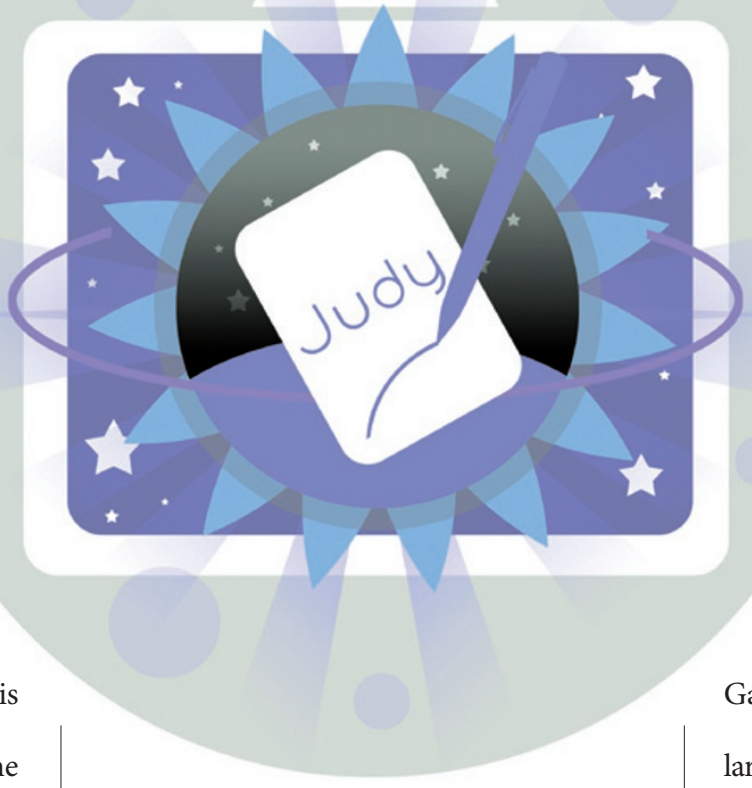

masses with plant covering. Apparently the CFC warming was a full-scale terraforming event, making a cold world habitable.

"So aliens are engineering their worlds," Judy said at a big international conference, while mobs outside fought over their differing views of these discoveries. The conference air-conditioning laboured so hard it was difficult to hear her. "Face it. Some go for warming, others cooling. But none of them emits strong radio or other waves, and no SETI broadcasts at all." She grinned. "I might point out that we're starting to spray sulphur dioxide into our stratosphere, and we don't send SETI signals either."

Her irony got buried under a media avalanche. Some said we should be guided by the wisdom of other smart species that had faced and solved their climate-change problems. Others pointed out that aerosols would not fix the ocean-acidification problem.
Their opponents said that throwing chalk into our seas could solve that. Within a week angry factions argued that geoengineering would directly betray us to aliens. Still more said this was all a hoax to get more funding.

Those astronomers keeping track of transits across the disks of stars reported another surprise. They had spotted something bigger than a planet orbiting an F star, but it wasn't round. The oblong profile showed no atmosphere clinging to it, but a shimmer revealed spectral lines implying that the construct was mostly made of carbon.

Building a Dyson sphere? the normally unimaginative New York Times headlined. This seemed to be confirmed a few months later when another oblong shell passed across the F star, this time in an orbit farther out than the first, and at a $40^{\circ}$ angle to the first orbital plane.

"This shows that aliens are builders," Judy said. But that was not all.

She continued her research, climbing to a top position at the University of California, San Diego. For decades she ran detection strategies for intense searches of billions of stars. She aged well, watching the gathering data, revealing dozens of astroengineering signatures spread across the Galaxy. She took up surfing.

Old fears resurfaced when Judy's everlarger team spotted a bright star that suddenly bloomed high above our ecliptic. It was plainly the fusion plume of a decelerating craft. Years later, the slim, magnetically webbed ship went into a high orbit above Earth.

They were spidery aliens who did no climate modification at all. They lived in elaborate cave labyrinths on a cool world that ran on geothermal power, but they liked to rove. They, too, had seen the immense engineering feats in their sky, and so had picked up on Earth's. They were neighbours, from only 23.6 light years away. Because they could directly monitor our low-power TV broadcasts, they knew the entire history of Judy's discoveries. They had become entranced with her.

They had come to talk. And maybe... an autograph?

Gregory Benford is a professor of physics at the University of California, Irvine, and a novelist. 